\title{
Disclosure of Sickle Cell Disease Results to Parents /Guardians Participating In a Research at a Hemato-Oncology Clinic in Eldoret Kenya
}

\author{
Peninah Jerotich Biwott ${ }^{1}$, Evangeline Njiru ${ }^{2}$, Violet Naanyu ${ }^{3}$ \\ ${ }^{I}$ (Department of Nursing, Moi Teaching and Referral Hospital, Kenya) (corresponding author) \\ ${ }^{2}$ (Department of Internal Medicine, College of Health Sciences, Moi University, Kenya) \\ ${ }_{3}^{3}$ (Department of Behavioral sciences, College of Health Sciences, Moi University, Kenya)
}

\begin{abstract}
Background: Disclosure is a key process in the management of sickle cell clients. This process if done well results in positive holistic ways of managing clients. However, if not handled well it can affect the client and the entire family both psychologically and emotionally, thus affecting the client's management. There is still an extensive debate regarding when and how to disclose genetic data to research participants in studies with a genetic component. Consequently, researchers and research ethics committee continue to struggle with the questions on whether research protocols should adopt provisions about disclosure of genetic data and if so, how it should take shape.

Objectives: The objectives were to identify the process of disclosure of sickle cell disease results, to determine the perception on the adequacy of disclosure process and to determine the ethical consideration in the disclosure process.

Methods: This was a cross sectional, qualitative study conducted at a Hemato-oncology clinic in a teaching hospital using key informant interviews and in-depth interviews.

Results: A total of (46) research participants and (5) research staff were interviewed. In view of disclosure process, the World Health Organization (WHO) six-step protocol was not adhered to and thus breach of confidentiality and fairness principles. Results showed that veracity as a principle was not addressed, since there was no specific team assigned to disclose results in the clinic, evidenced by 40/46 participants given results by the doctor alone. Out of 46 participants, 38 reported that they did not get emotional support, thus negating the principle of non-maleficence. On respect for persons, 36/46 participants reported that disclosure of information was inadequate. Confidentiality was maintained as reported by 44/46 participants and the principle of justice was observed since $40 / 46$ reported that their children received medication and showed great improvement. Most staff (3/5) believed breach of disclosure process was due to huge workload.

Conclusion: The study found that there was no consensus on who and how to disclose sickle cell disease results at the hemato-oncology clinic. The six-step WHO protocol was not adhered to and parents/guardians felt that the information given was inadequate. Ethical issues of beneficence, autonomy, veracity, non-maleficence and respect of persons were not well addressed. However, confidentiality was well observed.
\end{abstract}

Keywords: Disclosure of results, Ethical issues, Sickle cell disease, Research Participants, Parents/Guardians.

\section{Introduction}

Quality face-to-face communication between health care workers and their patients/clients is the most important medical procedure, as it leads to information transfer that affects patient's compliance, adherence, clinical outcomes and general client satisfaction [1]. There has been an extensive debate regarding when and how to disclose genetic data to research participants in studies with a genetic component; consequently, researchers and research ethics committees continue to struggle with the questions on whether research protocols should adopt provisions about the return of genetic data and if so, how this should take shape [2].

Sandy Oliver and team [3] argue that, it is evident that, a clear process on how to relay results to a research participant has not been established. Some researchers relay results through a phone call, some research participants receive their results directly from the laboratory with no explanations and others are given their results by the researchers in the clinical area. This is without considering privacy and psychological needs of the participant [3]. A study done by Hall et al. [4] clearly illustrated one of the main dilemmas inherent in disclosing carrier status, involving the issue of confidentiality. The debate emphasize on the issue of whom the information belongs, that is, the fact that the results should be disclosed to either the mother, father, the couple or the entire family. To address ethical issues and patient comfort, Baille and others [5] elaborated a six-step protocol, to follow during disclosure of bad news. These are; 
1. Setting up the interview that is arranging for privacy, involving the relatives and managing time constraints and interruptions.

2. Assessing, the patient/relatives perception.

3. Obtaining the patients perception that is, ensuring that the patient/relative understands well

4. Giving knowledge and information to the patient/relative.

5. Addressing the patient's emotions with empathic response

6. Strategy and summary.

The amount of information that should be given to research participants with genetic disorders is still under debate. It is not clear whether the information given to them currently is adequate or not. If researchers have life-saving genetic information of immediate clinical utility about a research participant, then a strong case in disclosing these results is made, grounded in the principle of beneficence, that is doing well for the sake of others [6]. He further argued that participants in studies are likely to learn that they are heterozygous carriers of more than one serious autosomal recessive disease, yet they do not know the reasons for refraining from having children. Adequate disclosure counseling, must consider the risk of stigmatization that carrier status represents, and this is based especially on cultural and social issues where heterozygous individuals are considered lesser persons in the society [2]. Bredenoord and team [2], further argues that disclosure should emphasize on emotional and psychological needs of Sicklers, and include - marital counseling before marriage of Sicklers, explaining pain episodes experienced in the course of their lifetime and priapism episodes experienced by male patients.

Vreeman, et al [7] argued that potential risks of disclosure for example fear, could negatively impact children and family psychological health, resulting in depression. Potential risks of disclosure have not been studied extensively in research limited resource setting. Since HIV is a lifetime disease just like sickle cell disease, disclosure has similar impact in both cases. It was thus important to carry out this study in order to determine the perception on the adequacy of disclosure process by parents/guardians of sickle cell research participants attending Hemato Oncology Clinic.

Dilemmas arise when a person's health care needs are not consistent with values held by others in society, persons with a genetic condition may prefer not to learn that their offspring is at risk for the condition. This presents an ethical dilemma for the clinician or researcher who must balance respect for the persons' wishes with his/her need to ensure that the couple and the client receive appropriate care [8]. There is no ethical justification for withholding test results. The fact that information maybe disturbing not just to the research participant, but also to the health care provider who has to convey it has not been proved. Most health care providers evade disclosure leaving a client with psychological torture [9].

Confidentiality as an ethical issue should be maintained at all cost during the disclosure process. The area used for disclosure should be private and conducive to the research participant during disclosure. It is an ethical responsibility to maintain participants' confidentiality. Several organizations have addressed the challenges of maintaining confidentiality in the genetic counseling setting [10].

In a study done on consulting communities on feedback of genetic findings in international health research, sharing sickle cell disease and carriers' information in Coastal Kenya, results indicated that perceived social and health benefits generated strong support for disclosing findings on the disease. However, the balance of social benefits and harms was less clear for sickle cell trait [11]. Despite extensive debate on disclosing genetic results, there is no consensus regarding when and how to disclose individual results to research participants with genetic components. Once there is genetic disorder discovery, the question then arises as to who and how to counsel the patient and/or family [12]. Therefore, it was necessary to assess the process of disclosure of sickle cell results to parents/guardians of research participants attending Hemato-oncology Clinic. Consequently, this study sought to find out ethical shortcomings in the disclosure process experienced by parents/guardians of sickle cell research participants attending the Hemato-Oncology Clinic of a teaching hospital in Kenya.

\subsection{Broad Objective}

To assess the process of disclosure to parents/guardians of children with sickle-cell disease enrolled in the sickle-cell study at AMPATH Hemato-oncology clinic

\subsection{Specific Objectives}

1. To identify the process of disclosure of sickle cell results to parents/guardians of children with sickle-cell disease enrolled in the sickle-cell study at the Hemato-oncology Institute.

2. To determine the perception on the adequacy of disclosure process by parents/guardians of children with sickle-cell disease enrolled in the sickle-cell study at the Hemato-oncology Institute.

3. To determine the ethical considerations in the disclosure process for parents/guardians of children with sickle-cell disease enrolled in the sickle-cell study at the Hemato-oncology Institute 


\section{Methodology}

A qualitative descriptive cross sectional study design was used to meet the objectives of this study. Key informant interviews and in-depth interviews were carried out using semi-structured questionnaires, with responses to interviews recorded verbatim.

\section{B. Setting}

The present study was carried out at a Hemato-oncology clinic in a teaching hospital located in Eldoret town, in Uasin Gishu County, Kenya. The hemato-oncology clinic has a sickle-cell clinic as one of the clinics that deals specifically with sickle cell patients from diagnosis, treatment and follow-up services. The clinic also serves as a center for research and among ongoing research is a clinical trial of hydroxyl-urea drug on sickle cell disease among children. The study currently has 62 enrolled research participants that formed part of the study participants.

\section{Sampling procedure}

Convenient sampling was used to identify parents/guardians for study based on their clinic appointments over a period of three months. While purposive sampling technique was employed to identify key informants (research staff) based on their direct involvement in the sickle-cell study at the hemato-oncology clinic. The (5) healthcare providers and the (62) parents/guardians of children having sickle cell disease enrolled in the sickle cell study participated in the current study. All patients enrolled for sickle cell care were below 18 years of age.

\section{Data analysis}

Data was transcribed, translated and analyzed using NVIVO software into themes and narratives that were then discussed in relation to past studies.

\section{E. Ethical considerations}

A formal approval on the study procedures was sought from the institutional research and ethics committee (IREC), and permission to carry out the study was obtained from the hospital administration and Hematooncology department prior to data collections.

III. 1 Socio-demographic data

\section{Results}

Descriptive results (Table 1) showed that majority of the parents/guardians of patients with sickle cell disease were females $37(80 \%)$ while minority were males $9(20 \%)$. The results indicate that females played a bigger role in taking care of the sick patients while attending the Hemato-oncology clinic. Most parents/guardians were found to be relatively young, with $41 \%$ and $35 \%$ aged between 30 and 40 years and less than 30 years, respectively. Only $24 \%$ of them were over 40 years.

The results (Table 1) showed that most patients were accompanied to the hospital by their parents $(\mathrm{n}=40,87 \%)$ compared with guardians $(\mathrm{n}=6,13 \%)$. The results implied that most of the children in the study had living parents. The number of individuals in each household ranged from a minimum of two to a maximum of 14 , with a mean of 5.12 and a SD of \pm 2 .

Majority of the parents/guardians had college/university level of education $21(46 \%)$, followed by those who had elementary/primary education 14(30\%). Those with secondary level of education comprised only $24 \%(\mathrm{n}=11)$. Most of the parents/guardians attending the Hemato-oncology clinics used public means of transport $40(87 \%)$ while only minority used private means $6(13 \%)$.

Most parents/guardians of patients diagnosed with sickle cell disease took about an hour to reach the health care facility, with a range of 10-300 minutes (5hrs) and mean time of 70 minutes.

Most parents/guardians of patients diagnosed with sickle cell disease are in formal employment 17 (37\%), followed by those who are self-employed 16 (35\%) and those that are unemployed $13(28 \%)$.

III.2 the Process of Disclosure of Sickle Cell Disease Information

III. 2.1 How the parent or guardian found out about the illness

Generally, most parents/guardian participants $(n=43)$ found out about the disease through the sickle cell study research staff at Moi Teaching and Referral Hospital. Before then there were several admissions in different hospitals with different diagnosis. For instance, a parent participant (04) recounted:

"First before I discovered she had sickle cell, she got admitted with malaria several times, so when she was two and a half years, a doctor in ....... told me that since the malaria was not resolving, we should go to ......for further tests.......is where a confirmatory test was done and is where I discovered that my child had sickle cell disease" 
Others knew about the sickness of the child after admission several times. Participant, guardian (16) stated; “ "...I brought the child to the hospital and was admitted for six days whereby he got malaria treatment with no much improvement. That is when the doctor decided that a sickle cell test be done. The child was enrolled in the sickle cell study and that is how I got to know that the child suffered from sickle cell"

However, one parent, participant (09) found out about the illness by studying the symptoms of the child. In the words of the parent:

"I knew this disease because after I delivered, when she started walking her eyes turned to yellow. I brought her to clinic here in referral and the doctor said it could be sickle cell, I told the doctor that I also expected the same since my first born had sickle cell. I had also been told that when I will deliver another child and becomes a girl, most likely she would have sickle cell. I already had two boys after my first-born and they were okay. Since I had seen the signs and it was similar to what my first born first born had, I was prepared for a positive result.........the sickle cell test confirmed so."

III. 2.2 Communication Process

When the respondents were asked how results of sickle cell disease were communicated to them; the study found that results on sickle cell disease was communicated to them mainly by oral means $(n=43)$, in which health care providers explained to parents and guardians on a one on one interaction. Only a paltry of the parents/guardians, one parent $(n=1)$ and two parents/guardians $(n=2)$ were told of the sickle cell condition through telephone or by mail means, respectively.

For instance, one guardian participant (27) reported thus;

“..., he came with the results we were called inside, he read the sickling test and said it was positive;.....Yeah, so it was a one on one interaction".

Written results were put in an envelope and given to parents. For example, parent participant (09) thus reported; "Yeah we came to the hospital, blood was drawn from the child, took to ........... Then we came for the results and we were given in an envelope, I opened, read the results and took it to the doctor"

III.2.3 The Person Communicating Sickle Cell Disease Information

It was found that doctors were the main people $(n=40)$ who conveyed sickle cell disease information to the parents. For example, one parent participant (39) remarked, thus;

"The doctor..... When they did a confirmatory test here, it is the doctor who gave us the results "

The study found that nurses could be conveying sickle cell disease information to clients because doctors might not be readily accessible. For example, one health care provider (01) reported that;

"The nurses...............Many at time I relay information to clients since they come through me before they go to the doctor, if the patient also comes to the clinic on a day that is not a clinic day, I relay the information since the doctor is unavailable".

III.3 Expectation on the results

Eight out of every 10 respondents, i.e. parents/guardian $(n=38)$ answered that the sickle cell results they received were at variance with their expectations. Only two out every 10 participant expected the results that they received.

One parent/participant (14), who did not expect the child to have sickle cell anemia, reported;

Actually, I did not expect she could have sickle cell because, there is no history in our family, so it was a shock to me but with time, I accepted.

There were parents who were not surprised by the results they received, this is because their older children had the same condition. For instance, one participant /parent (22) stated that:

"I knew about it, so I was not that shocked because my first born died of sickle cell"

Others expected the worst because the child had a history of recurrent illnesses. One guardian participant (42) explained: "Me I was expecting anything because he has disturbed me since January"

III.4 Perceptions of Health Care providers on the Disclosure Process

One of the health care providers (03) reported that, for a client to be enrolled to the study, a confirmatory test has to be done. If positive, then disclosure process began from here. During the initial encounter with the client, a little information on sickle cell is given then; information is delivered in portions throughout the entire study. He reported that;

So before we communicate the results, we need a confirmatory test....... so personally how I usually go about is, they come with sickling test which is positive, I just give them a little bit information because for them, it's a big concern that they have something that reads positive but you don't tell them 100\% they have sickle cell disease until they have Hb electrophoresis as confirmation"

The clinicians reported that, the key persons that preferred information disclosed to them were the primary caretakers, preferably both parents. This helped address the issue of genetic transfer of disease and helped avoid blame game. The clinicians however had challenges in disclosing information to both parents of the afflicted 
children because of the African culture, where children are often brought up by their mothers. One of the clinician (04)reported that; ".........In the African culture, the common problem is that everybody who brings in the patient the next time wants information, so I usually want to ask who the primary care taker of this patient is. It is good when both parents are there because with sickle cell disease there is a lot of blame game like it came from the fathers' or mothers side. It's hard to bring both of them together because of just generally the technicality of our African settings. The mother usually brings the baby but sometimes you get very interested fathers and they bring the baby together. We have also had families where, because sickle cell disease runs in families you can find a few orphans, they have the care takers so it's important to have to know the person whom you are going to relay the information to"....."We need community education concerning sickle cell disease"

On the delivery of sickle cell information, one research staff/nurse (01) reported that she delivered results through a phone call; one reported that she delivered results in a written form, while four research participants $(02,03,04$, and 06) reported that they preferred one on one delivery of results. One of the research staff (05) reported that she should be the one disclosing the results since she first encounters the client. On the other hand, a research staff reported that it should be the work of the clinician to disclose research findings. One nurse (01) reported that;

"The nurses...............Many at times I relay information to clients since they come through me before they go to the doctor..."

However, three of the research staff $(01,03$ and 05$)$ reported that disclosure should be collaborative; they felt that a genetic counselor, a psychological counselor should be brought on board. One of the health care provider reported that; "I think the other challenge is that when you are working in the clinic you have a queue of patients probably you never spend enough time explaining the diagnosis and addressing psychological issues. So I think that a genetic counselor, nurse and psychological counselor should come in handy to participate in a collaborative disclosure"

All the research staff reported that they go through psychological distress when delivering results to some participants. This was especially so in cases where both parents suffer the disease. One of the research staff (01) reported that;

"she first hang up on me and then I called after sometime, she didn't pick my calls, gave a few more minutes, like one hour passed then she called back and she was like what were you saying.... so I broke the news to her, it was very devastating for her and I felt like I caused the parents distress. I felt like I had been given bad news myself, after breaking such news to two or three clients and get such reactions, I breakdown and do not feel comfortable breaking news to other parents or guardians. I feel we need psychological support also as health care providers.

III.5 Adequacy of Disclosure.

III.5.1 Information Parents want to know during disclosure

The study found that respondents wanted to know various aspects of sickle cell disease during the disclosure process. Such information included the existence of discrepancy in results, the best nutrition for sickle cell patients, relationship between fever and sickle cell, and the lifespan of the one suffering from sickle cell. Others included whether somebody should disclose sickle cell condition when dating, if a sickle cell patient could get children, how the disease can be prevented, whether family members can be carriers, whether sickle cell is curable, and how one can manage the condition in order to live long.

For instance, a parent participant (35) stated:

"....I wanted to know what causes the disease..............will the disease get cured completely? What if I get another pregnancy, will the baby be affected...

Another health care provider (04) added that:

"So when they come, most of them already had an idea of what their children are suffering from. You see it is not like any other disease that you can have and do not know what it is. So up to $90 \%$ already know that they have sickle cell disease, but they don't have an understanding of the disease, so our role at that time is not to disclose the disease but just to explain it to them so that they understand more about it".

On if it was curable, a guardian participant (19) explained;

"They normally say at the age of eighteen sickle cell is over 'I wanted to know if it was true and if she will use sickle cell drugs for life."

Participants wanted to know how to manage sickle cell for one to live long. One parent participant (07) inquired;-

"Wanted to know if the disease is inborn or acquired, and how it can be managed"

Participants who were ignorant of sickle cell disease were the ones likely to consider information given during disclosure as being inadequate. Most of those who asked questions after the interview about sickle cell disease argued that information given to them was inadequate. For instance, one of them, parent participant (40) put it that; 
"I felt I needed more time because someone will give you information expecting that you already know about sickle cell, we went to clinic and we were told some test will be done, was not told which ones and most times, you find a different doctor"

One of the health care providers $(03)$ reported that;

"I think the other challenge is that when you are working in the clinic you have a queue of patients probably you never spend enough time explaining the diagnosis so I think that's where the genetic counselor should come in handy as they will have entire day doing disclosure unlike a clinician who has other responsibilities.

III.5.2 Adequacy of time used during disclosure

Participants felt that doctors had too many patients, which reduced the time medical officers could dedicate to an individual parent in explaining sickle cell results. One parent participant (13) reported thus;

“.......He had a lot of patients, it was after noon at two o'clock, and people were many who had been given appointment that day so he taught us little...........I felt I needed more time because someone will give you information expecting you already know.... Because we went to clinic and we were told some tests will be done, we did not understand which tests and anytime you find a different doctor"

Parents who already had an inkling of the results (for instance, those whose older children had sickle cell) required less time in the disclosure process. For instance, one of the guardian participants (17) who considered the time as adequate stated;

"Yes I needed no more time because I already knew the results".

The lack of time also ensured that most participants $(n=38$,$) were not engaged during the disclosure process.$ One participant-parent (02) explained:

"No, he [doctor] came with the results, we were called inside, he read the results, he read the sickling test and said results was positive, so your child has sickle cell, that way, he added nothing more, I broke down......... but the doctor was busy so there was no emotional support. I wish there was a psychological counselor"

Another guardian participant (31) replied,

"He had a lot of patients; it was after noon at two o'clock people were many who were given appointment that day so he taught us little"

Most participants $(n=30)$ noted that they were not given enough information on how the child will be managed, and clinicians felt they did not spent enough time with the participants. One parent participant (26) reported that; "No, I just followed the instructions from the doctor".

Health care professional (03) also reported that:

"I think the other challenge is that when you are working in the clinic you have a queue of patients probably you never spend enough time explaining the diagnosis so I think that's where the genetic counselor should come in handy as they will have entire day doing disclosure unlike a clinician who has other responsibilities"

III.5.3 Feelings after disclosure

The study found that parents and guardians experienced varied emotions upon learning of the presence of sickle cell anemia in their children. The feelings included being bored, bitter, normal, devastated, angry, surprised, sad, helpless, annoyed, painful, and feeling nothing.

Several participants had this to say;

Surprised: Some participants were surprised to hear that one of their siblings was a sickler. A parent Participant (22) reported:

"What?!..... I have never imagined this, the way my two other siblings died with the same symptoms yet in my health centre was always told that it is malaria..... Please come and educate our people because most of my relatives have been dying with the same problem and we are told it is malaria. We have even imagined it could be witchcraft following us as a family........"

Normal: a parent participant (1) reported that,

"Aaah..... I just said it is okey! It is normal in Nyanza eeh.... I the mother is a Luo, and there it is common, so me I understood, but her father felt bitter since he is a Luhya, I was like it has happened"

Depression: A parent participant (19) reported that, "aaah I was so depressed........sobbing...... did not talk to people for some time, since I also lost another child with the same problem, so depressing indeed"

Devastated: One of the health care providers (01) reported that,

"she first hang up on me and then I called after sometime, she didn't pick my calls, gave a few more minutes like one hour passed then she called back and she was like what were you saying.... so I broke the news to her, it was very devastating for her and I felt like I caused the parents distress. I felt like I had been given bad news myself.

Of those who felt disturbed, one of the participants added:

Disturbed: A parent Participant (20) reported feeling disturbed on receiving the information their children had sickle cell disease. 
"it disturbed me because you know my son is not the first born ,my first born died and she is the second born, so every day we went to hospital the blood is insufficient, I have donated to her three times, getting A-positive blood group is hard"

A typical participant-guardian (38) who agreed that follow-up was done said thus;

"Yes follow up is going on, currently she is okay, I have not seen any problem with follow up"

The single parent participant (6) who noted that follow-up was not done said;

"No I would just bring her to hospital when she felt sick"

III.5.4 Perception of Health Care Providers on the Adequacy of Information Disclosed and psychological

impact.

Three of the research staff $(01,02$ and 03$)$ reported that, time spent with a client is a challenge since there is a long queue of patients; they thus felt that enough information was not relayed to the clients. Investigators, medical officers and nurses were involved in identifying the patients recruited and disclosing results to the parents/guardians. The study also shows that the health participants disclosing results undergo psychological distress after disclosing to some participants. Health care providers suggested that there should be a psychological and genetic counselor brought on board during disclosure. One of the research staff (02) was quoted saying:

"I share with my colleagues the Doctors whom we are managing the patients with and eeeh mostly, the nurses because they have been of much support to me, because it has not been easy to handle some emotions, at times I break down after disclosing..... feel that we should have a psychological counselor and a genetic counselor on board.

Research staff (01) reported that....... I have been sharing with the doctors and sometimes we wonder how best we can improve breaking the news. Many a times I have found that I am actually the person who breaks the news because patients come through the nurse before they get to doctor so, I sometimes take them to the doctors room so that we break the news together with the doctor, especially when I feel that I may not be able to disclose alone.... Ifeel we need a psychological counselor"

All health care providers revealed that, they had challenges during disclosure, which included family conflicts. One research staff (03) stated that;

"Wow that's difficult to tell because it's not an easy report to give to a parent or a guardian and especially for those who are inter-married. May be for those who come from the same community and sometimes you have parents married from different communities that may have been having issues intermarrying with other communities. So it has not been easy most of the time, I sincerely confess sometimes am not ready to break the news because this is just breaking bad news to the parent".

III.5.5 Tests used to Screen Sickle Cell Disease

The study found that for most parents/guardians their children $(n=45$,$) two tests were utilized to screen for the$ disease: first, a Sickling test for initial analysis and a Hemoglobin ( $\mathrm{Hb}$ ) Electrophoresis test for confirmatory investigation. For example, a health care provider (03) reported;

".....and eeeh we have the screening test which is a Sickling test then we have a confirmatory test Hb electrophoresis. So usually, before we communicate to a client we ensure that we have a confirmatory test, which is $\mathrm{Hb}$ electrophoresis. Many of them are usually referred to us with a positive sickling test and then we have to go ahead and confirm for them. So before we communicate the results we need a confirmatory ....... so personally how I usually go about is, they come with sickling test which is positive, I just give them a little bit information because for them it's a big concern that they have something that reads positive but you don't tell them $100 \%$ they have sickle cell disease until they have Hb electrophoresis as confirmatory"

III.6 Ethics of the Disclosure Process

The study investigated a triad of major ethical issues: confidentiality, consenting, and whether justice was observed. These findings were bolstered by face-to-face interviews. One parent participant (43) who felt that the disclosure process lacked confidentiality felt that results were written on a piece of paper that was not enclosed in an envelope said thus;

"No! results are just given to you in a paper with no envelop to take to the doctor for interpretation" and "No he gave me when people were there, said the results were positive and that the doctor will tell me later, he didn't call me alone"

Typical participant (10) who felt that proper consenting was not done and thus justice denied said the following; "He didn't tell me why it was necessary to be in the study........." me I want my child to benefit and the doctor is always right..... "When signing he said, when we come back next time he will explain to us.....because the queue is long........

Research participants felt that justice as a principle was observed. A parent participant (25) reported that:mm....... am happy being in this study because my child gets hydroxyl urea free of charge..... 


\section{III.7 Summary of results}

The general objective of this study was to assess the process of disclosure given to parents/guardians of children with sickle-cell disease enrolled in the sickle-cell study at a Hemato-oncology clinic in a teaching hospital in Kenya. Specifically, the study aimed to identify the process in disclosure, determine the perception of the adequacy of the process and determine the ethical considerations in the disclosure process.

The study found that results on sickle cell disease was communicated to participants mainly by oral means $(\mathrm{n}=43,94 \%)$, in which health care providers explained to parents and guardians on one-on-one interaction. Only a paltry $2 \%(\mathrm{n}=1)$ and $4 \%(\mathrm{n}=2)$ of the parents were told of the sickle cell condition through telephony or by written means, respectively. Parents who received written communication on sickle cell condition were likely to be college/university educated whereas those who were told results orally were likely to be female, have elementary or secondary education, and be either unemployed or self-employed. Doctors are the main people $(87 \%, \mathrm{n}=40)$ who convey sickle cell disease information to the parents, with only $13 \%(\mathrm{n}=6)$ communicated to by nurses. Generally, most participants $(n=43,93 \%)$ found out about sickle cell anemia through hospital tests after several admissions following the ailment of their children. Eight out of every 10 respondents did not expect that their children would be diagnosed with sickle cell whereas the rest expected the results.

The study showed that more respondents $(\mathrm{n}=26,57 \%)$ felt that the information they received was not adequate. compared to those who thought that it was $(n=20,44 \%)$. The perception about the adequacy of information received was not significantly associated with any biographical category, that is, regardless of the respondents' gender, age, education, and occupation, more of them always felt that the information provided during the disclosure process was not enough. An overwhelming proportion of respondents $(n=38,83 \%)$ felt that the time used in the disclosure process was not adequate compared to those who thought that it was $(n=8$, $17 \%$ ).Young, self-employed female mothers, with both college and elementary education, are likely to consider the time given for the disclosure process as being inadequate while older participants were likely to find the time used as being adequate. Parents experienced varied emotions upon learning of the presence of sickle cell anemia in their children such as being devastated, disturbed, angry, depressed, surprised, and normal.

The study showed that most participants $(n=31,67 \%)$ felt that confidentiality was maintained relative to those who answered that it was not $(\mathrm{n}=15,33 \%)$. In addition, six out of every ten respondents $(61 \%)$ felt that justice was observed during the consenting process. However, majority of the participants were of the opinion that the consenting process was not proper $(n=27,59 \%)$ compared to those who felt that it was $(n=19,41 \%)$. Participants who felt that confidentiality was not maintained during disclosure were likely to be well educated (college or university), employed and middle aged parents.

\section{Discussion}

The study found out that, results on sickle cell disease were communicated to parents and guardians mainly by oral means in one-on-one interaction with only a few parents being informed through telephony or written means. The results indicated that females played a bigger role in taking care of the sick patients while attending the clinic. This supports a study done in South Africa in regard to family role in taking care of the sick, which showed that females play a major role [13]. Baille and others [5] came up with a six-step strategy for delivering bad news, in order to support the patient and enable an appropriate future strategy for managing the condition. These included setting up the interview (by arranging for privacy and making connection with the patient), assessing the perceptions of the client, obtaining the patients/relatives/parents invitation, done by giving the parents the opportunity to know what they desire to know, and providing knowledge and information to the patient. Others were, addressing the patient's emotions with empathic responses done by connecting the emotions with reason by making a connection statement and lastly, discussing with patient/relative if they are ready for the discussion and giving them a way forward. The fact that most parents are given information in a one on one-interaction with medical practitioners suggested that some steps in the procedure, for instance, interviews and discussion with patients, are followed [5]. However, it is doubtful that the whole elaborate process is followed. This was because the process was hurried, as some participants reported that the doctor just came with the results and said that it was positive, without any preparation. Thus, this study, like Sandy Oliver et al. [3], reports that health care practitioners may not be following the full disclosure process, because of the pressure of time or busy schedules, such that their clients might not be obtaining complete information or emotional support in case of positive diagnosis. According to Henley and colleagues, the quality of face-to-face communication between health care workers and patient/client is the most important medical procedure, as it leads to information transfer that affects patient's compliance, adherence, clinical outcomes and general client satisfaction [14]. It therefore follows that if these sessions are turned into merely "one-minute encounters", in which the health practitioner essentially reads out the results of the sickle cell condition, they might not be achieving their intended aim - which is to disclose all necessary information in an emotionally supportive environment. It was satisfactory that the oncology clinic used only a few instances in which the respondents 
were communicated to by either written means or telephony. However, the fact that these relatively impersonal means were used at all suggested that personal connection between the discloser and the client might not have been achieved. The study found out that doctors were the main people who conveyed sickle cell disease information to the parents. However, in some cases, nurses also passed the information to clients. Traditionally, the duty of transmitting medical information to patients has rested with doctors, however, nowadays, nurses and other medical practitioners have played an increasing role [15].Edwards and team [15], investigated parents' perception of how health professionals communicated in an interview of 20 mothers and 17 fathers whose babies were one-week old in neonatal unit. They reported that parents felt that nurses communicated better than doctors did. Nurses were found to be more effective when they changed their behavior or conversation to meet the needs of parents. Norgaard et al [16] found that parents believed that doctors did an excellent job in providing them with information about their sick children. The latter study [16] also reported that nurses spent the most time with parents, explained their child's condition to them and were their principal source of information. Thus, it appears that who presents information - doctors or nurses - might not be important. What is pertinent is that the information must be accurate and detailed and be delivered by a person with a pleasant, attentive and caring attitude. The study findings thus found out that a collaborative team is vital in disclosure. On adequacy of information, more respondents felt that they were given inadequate information and this was reported by every category of biographical variable. This concurs with a study done by Bredenoord and others [2], where it was argued that the amount of information given to research participants with genetic disorders is still under debate. However, it is generally accepted that if researchers have life-saving genetic information of immediate clinical utility about a research participant, then a strong case can be made disclosing these results grounded in the principle of beneficence, which is doing well for the sake of others [2]. Parents for instance wanted to know about the best nutrition for sickle cell patients, relationship between fever and sickle cell, and the lifespan of the one suffering from sickle cell. Others included whether somebody should disclose sickle cell condition when dating, could a sickle cell patient get children, how can the disease be prevented, can family members be carriers, is it curable, and how can one manage the condition in order to live long. The study found that this information was inadequately delivered at the clinic. In a study conducted in the coastal region of Kenya [11], showed that perceived health and social benefits generated strong support for disclosing results on sickle cell disease. It is therefore crucial for adequate information to be given to parents in order to redeem these benefits. This is especially so to parents who were ignorant of the disease.

The chief reason for the paucity of information appears to be lack of time, with participants feeling that doctors had too many patients, which reduced the time medical officers could dedicate to an individual parent in explaining sickle cell results. This conclusion is supported by the fact that the study found an overwhelming proportion of respondents who felt that the time used in the disclosure process was not adequate. Clinicians themselves felt they did not spent enough time with the participants. This could be detrimental because the study showed that even parents with no or modest education were given only bits of information [17].The study reported that disclosure of results came with burdens, for instance, considerable time preparation are required if results are to be comprehensively disclosed to lay audience. It might be helpful that if doctors are too busy because they are fewer, experienced and knowledgeable nurses and other medical officers could be drafted to help in disclosure. The study found that there were frequent changes in doctors, with the one carrying out the initial test often different from the one conveying the results. Consequently, a longer lasting, potentially trustful, and emotionally supportive relationship between a parent and a doctor, as espoused by Graves et al. [18], was never established. It may therefore not be surprising that the parents in this study experienced harrowing emotions upon learning of the presence of sickle cell anemia in their children such as being devastated, disturbed, and depressed. Oliver and team [3] suggested that in spite of counseling, receiving an initial screen positive result for sickle cell disease can be difficult to understand and leads to anxiety, confusion and depression. It is true that receiving harrowing information about a life-long genetic disorder will be a cruel blow to anyone. However, the blow will be lessened by counseling as it happens with HIV - AIDS disclosures [19]. Indeed, medical practitioners in the hemato-oncology hydroxyl urea study advised that psychological counselors should be involved in the disclosure process.

Regarding ethical issues, the study showed that most participants felt that confidentiality was maintained during disclosure. Sickle cell, just like HIV - AIDS is a lifetime disease, and hence the ethical question of who should be given information is pertinent. In a sickle cell study [20] raised the question of to whom the information belongs: the child, the mother or the couple. Generally, physicians only have duties to their patients (in this case, the children), and, unless a patient expressly consents to disclosure or a law requires it, they are obliged to hold patients' medical information in the strictest confidence [21]. Given that the clients in this study were children, the hemato-oncology Clinic is right to disclose the information to their parents. However, the issues reported by this study, for instance, publicly telling parents that their children have sickle cell or not enclosing the test results in an envelope might be ill advised. The fact that participants who felt that 
confidentiality was not maintained during disclosure were likely to be well educated (college or university), employed and middle aged parents, suggested that they were the ones who were discerning enough to the fact.

In addition, six out of every ten respondents felt that justice was observed during the consenting process. However, majority of the participants were of the opinion that the consenting process was not proper. Other researchers $[19,22]$ have noted that deficiency of informed consent continues to be ignored and its practice remains an issue of concern.

\section{Conclusion}

The present study identified that the WHO six step protocol is not adhered to during disclosure of genetic disorders to patients and relatives in health care institutions. Most respondents further felt that inadequate information on genetic disorders was made available to them mainly due to limited time that healthcare providers are willing to spend on the disclosure process.

\section{Recommendations}

In the light of the main study finding, the following recommendations are proposed.

- The six- steps protocol in the disclosure process should be integrated in the standards operating procedures genetic disorders disclosure as each of the stage has a pertinent function.

- Health care providers should convey adequate information about genetic disorders to their clients and strive to project a caring, understanding and pleasant attitude.

- Health care institutions should allow a collaborative team of doctors, nurses, genetic and psychological counselors to participate in disclosure.

- Psychological counselors should be incorporated in the clinic to offer continuous counseling on lifelong genetic disorders since they can be traumatizing to the client.

- Health care institutions should set aside disclosure rooms to strengthen confidentiality between practitioner and patient.

\section{Acknowledgements}

The first author thanks the second and third authors (Dr. Evangeline Njiru and Prof. Violet Naanyu) for their exemplary guidance and support in development and writing of this thesis, as part of partial fulfilment of a master's degree at the Moi University. She also thanks Professor David Ayuku and Professor. Eric Meslin, Director, IUCB and PI, IU-Moi AREP and Fogarty international center for sponsoring part of the Msc. IHRE program. Finally, she acknowledges all family members and friends for their financial and moral support during the studies.

Table 1: Demographic Data of Respondents

\begin{tabular}{|c|c|c|c|}
\hline $\begin{array}{l}\text { PANEL A } \\
\text { BIO-GRAPHIC INFORMATION OF RESPONDENTS }\end{array}$ & CATEGORIES & FREQUENCY & Percent \\
\hline \multirow{3}{*}{ GENDER } & MALE & 9 & 19.6 \\
\hline & FEMALE & 37 & 80.4 \\
\hline & TOTAL & 46 & 100.0 \\
\hline \multirow{4}{*}{ AGE } & LESS THAN 30 YEARS & 16 & 34.8 \\
\hline & $30-40$ YEARS & 19 & 41.3 \\
\hline & OVER 40 YEARS & 11 & 23.9 \\
\hline & TOTAL & 46 & 100.0 \\
\hline \multirow{3}{*}{ RELATIONSHIP TO PATIENT } & PARENTS & 40 & 87.0 \\
\hline & GUARDIANS & 6 & 13.0 \\
\hline & TOTAL & 46 & 100.0 \\
\hline \multirow{4}{*}{ LEVEL OF EDUCATION } & ELEMENTARY & 14 & 30.4 \\
\hline & SECONDARY & 11 & 23.9 \\
\hline & COLLEGE & 21 & 45.7 \\
\hline & TOTAL & 46 & 100.0 \\
\hline \multirow{3}{*}{ MEANS OF TRANSPORT WHEN VISITING HEALTH FACILITY } & PUBLIC MEANS & 40 & 87.0 \\
\hline & PRIVATE MEANS & 6 & 13.0 \\
\hline & TOTAL & 46 & 100.0 \\
\hline \multirow{4}{*}{ TYPE OF EMPLOYMENT } & UNEMPLOYED & 13 & 28.3 \\
\hline & SELF-EMPLOYED & 16 & 34.8 \\
\hline & FORMALLY EMPLOYED & 17 & 37 \\
\hline & TOTAL & 46 & 100.0 \\
\hline $\begin{array}{l}\text { PANEL B } \\
\text { BIO-GRAPHIC INFORMATION OF RESPONDENTS }\end{array}$ & RANGE & MEAN & STD. DEV. \\
\hline HOUSEHOLD SIZE $(\mathrm{N}=46)$ & $2-14$ & 5.12 & 2.29 \\
\hline TIME TAKEN TO REACH HEALTH FACILITY $(\mathrm{N}=46)$ & $10-300$ MINUTES & 70.35 MINUTES & 58.32 \\
\hline
\end{tabular}




\section{References}

[1] S Ashida, LM Koehly, J.S Roberts, CA Chen, S. Hiraki, and RC Green, Disclosing the disclosure: factors associated with communicating the results of genetic susceptibility testing for Alzheimer's disease. Journal of Health Communication, 14(8), 2009, $768-84$.

[2] AL Bredenoord, HY Kroes, E Cuppen, M Parker, and JJM van Delden, Disclosure of individual genetic data to research participants: The debate reconsider. Trends in Genetics, 27(2), 2011, 41-47.

[3] S Oliver, C Dezateux, J Kavanagh, T Lempert, and R Stewart, Disclosing to parents newborn carrier status identified by routine blood spot screening. Cochrane Database of Systematic Reviews (Online), (4), 2004. CD003859.

[4] MA Hall, SS Rich, K Abraham, J Alper, J Beckwith, and M Yesley, Laws restricting health insurers' use of genetic information: impact on genetic discrimination. American Journal of Human Genetics, 66(1), 2000, 293-307.

[5] WF Baile, R Buckman, R Lenzi, G Glober, EA Beale, and AP Kudelka, SPIKES-A six-step protocol for delivering bad news: application to the patient with cancer. The Oncologist, 5(4), 2000, 302-11.

[6] N Kamani, M Walters, S Carter, and V Aquino, Unrelated donor cord blood transplantation for children with severe sickle cell disease: Results of one cohort from the phase II study from the Blood and marrow transplant clinical trials network. Biology of Blood and marrow transplantation, 18(8), 2012, 1265-1272.

[7] RC Vreeman, ML Scanlon, A Mwangi, M Turissini, SO Ayaya, C Tenge, and WM Nyandiko, A cross-sectional study of disclosure of HIV status to children and adolescents in western Kenya. PloS One, 9(1), 2014, e86616.

[8] AL Ersig, DW Hadley, and LM Koehly, Colon cancer screening practices and disclosure after receipt of positive or inconclusive genetic test results for hereditary nonpolyposis colorectal cancer. Cancer, 115(18), 2009, 4071-4079.

[9] D Chelagat, and E Kulei, Caring for Carers in Palliative Care. International Journal of Humanities and Social Science, 3(11), 2013.

[10] BD Riley, JO Culver, C Skrzynia, LA Senter, JA Peters, JW Costalas, and AM Trepanier, Essential elements of genetic cancer risk assessment, counseling, and testing: Updated recommendations of the National Society of genetic Counselors. Journal of Genetic Counseling, 21(2), 2012, 151-161.

[11] V Marsh, F Kombe, R Fitzpatrick, TN Williams, M Parker, and S Molyneux, Consulting communities on feedback of genetic findings in international health research: sharing sickle cell disease and carrier information in coastal Kenya. BMC Med Ethics, $14: 41,2013$.

[12] M Harris, I Winship, M Spriggs, T Beauchamp, J Childress, and K Offit, Controversies and ethical issues in cancer-genetics clinics. The Lancet. Oncology, 6(5), 2005, 301-10.

[13] R Homan, C Searle, E Esu-Williams , M Aguirre, S Mafata, F Meidany, C Oosthuizen, L Towel, Family care givers. Exploring the role of family caregivers and home-based care programs in meeting the needs of people living with HIV/AIDS," Horizons Research Update, 2004. Johannesburg: Population Council

[14] A. Henley, J. Schott, and D. Opoku, Culture, Religion and Childbearing in a Multiracial Society: a handbook for health professionals (Oxford: Butterworth Heinemann, 1996. 6th Edition).

[15] D Edwards, W Smyth, R Jones, C Wainwright, C Branch-Smith, K Wicking, and L Shields, Protocol For Study Of Information Needs Of Parents Of Infants Newly Diagnosed With Cystic Fibrosis (8 No. 1). 2014.

[16] B Nørgaard, E Draborg, E Vestergaard, E Odgaard, D Cramer Jensen, and J Sørensen, Inter-professional clinical training improves self-efficacy of health care students, 2(35), 2013, 1235-1242.

[17] CV Fernandez, E Kodish, and C Weijer, Informing Study Participants of Research Results: An Ethical Imperative. IRB: Ethics and Human Research, 25(3), 2003, 12.

[18] KD Graves, PS Sinicrope, MJ Esplen, SK Peterson, CA Patten, and J Lowery, Behavioral Working Group of the Colon Cancer Family Registry. Communication of genetic test results to family and health-care providers following disclosure of research results. Genetics in Medicine : Official Journal of the American College of Medical Genetics, 16(4), 2014, $294-301$.

[19] G. Mabunda, Ethical issues in HIV research in poor countries. Journal of Nursing Scholarship : An Official Publication of Sigma Theta Tau International Honor Society of Nursing, 33(2), 2001, 111-4.

[20] SK Ballas, Ethical issues in the management of sickle cell pain. American Journal of Hematology, 68(2), 2001, $127-132$. http://doi.org/10.1002/ajh.1164

[21] SM Liao, M Sheehan, and S Clarke, The Duty to Disclose Adverse Clinical Trial Results. The American Journal of Bioethics, 9(8), 2009, 24-32.

[22] PA Marshall, (2007). Ethical challenges in study design and informed consent for health research in resource-poor settings (Special Topics in Social, Economic and Behavioral (SEB) Research report series No. 5). 